\title{
The Importance of Keeping Pesticide Records ${ }^{1}$
}

\author{
F. M. Fishel ${ }^{2}$
}

\section{Introduction}

Keeping accurate records of pesticide use makes good sense. In some cases, you are required by law to maintain records on pesticide use, but having records available can also help you improve your operation. For example, records can assist you with the following:

- To evaluate how well a chemical worked, particularly if you used reduced rates or alternative application techniques

- To determine how much pesticide you will need in a future year, so that you will not have to store or dispose of extra chemicals

- To prevent carryover injury and improve rotation decisions

- To possibly protect you from legal action if you are accused of improper pesticide use

- To give to food processors as required for evaluating the potential for residues

- To provide required information to lenders and land developers to evaluate potential environmental liability before lending money or buying land
- To provide data to respond to surveys conducted by federal agencies and universities that can impact the re-registration and availability of some pesticides

- To respond to the public's concern regarding pesticide use

- To save money by helping a manager determine the best pesticide management program

Records are the key to a successful integrated pest management program. Although the required contents of a pesticide application record have many similarities, there are some key differences in records depending on federal and Florida law (Table 1). Many pesticide applicators and handlers are required to maintain multiple records, depending on the activities in which they are involved. This publication outlines who is required to keep records of pesticide use and the appropriate contents.

\section{Public Health Pest Control (Ch. 388, F.S.)}

\section{Ground Applications}

Public health pest control applicators must keep accurate records so the Florida Department of Agriculture and Consumer Services (FDACS) can assess monthly activity

Table 1. Applicator groups according to the law and regulating agency.

\begin{tabular}{|l|l|l|}
\hline Applicator group & Florida law & Florida agency \\
\hline Public health pest control & Ch. $388-$ Florida Statutes & $\begin{array}{l}\text { Florida Department of Agriculture and Consumer Services (FDACS) Bureau } \\
\text { of Entomology and Pest Control }\end{array}$ \\
\hline Structural pest control & Ch. 482 - Florida Statutes & FDACS Bureau of Entomology and Pest Control \\
\hline Agricultural pest control & Ch. 487 - Florida Statutes & FDACS Bureau of Compliance Monitoring \\
\hline
\end{tabular}

1. This document is PI246, one of a series of the Agronomy Department, Florida Cooperative Extension Service, Institute of Food and Agricultural Sciences, University of Florida. Original publication date May 2013. Visit the EDIS website at http://edis.ifas.ufl.edu.

2. F. M. Fishel, professor, Agronomy Department, and director, Pesticide Information Office; Florida Cooperative Extension Service, Institute of Food and Agricultural Sciences, University of Florida, Gainesville, FL 32611. 
reports with information regarding pesticide applications, source reduction, water management, biological control, and surveillance activities. These records must be kept for a minimum of three years and include the following:

1. Name of applicator

2. Pesticide and amount used

3. Method of application

4. Location of application

5. Application rate

6. Date and time of application

7. Surveillance method and data providing justification for any adulticide applications

\section{Aerial Application of Adulticides}

After an aerial adulticiding operation takes place (chemical treatment for adult mosquitoes), records must be maintained for a minimum of three years and at least include the following:

\section{Area treated}

2. Application rate and material used

3. Equipment and technique used

4. Name of the pilot in command

5. Date, time, temperature, and general wind speed and direction

6. Pretreatment and post-treatment records of mosquito and other arthropod presence, including:

- Number and type of trapping and surveillance methods used

- Trap and surveillance site locations

- Pretreatment and post-treatment trap catches, landing rates, or surveillance levels by mosquito species involved

7. Apparent non-target effects

\section{Aerial Applications during Declared Emergencies}

Aerial mosquito control applicators must maintain records relating to each pesticide application during a declared emergency. The records generated during the emergency must be retained for a two-year period and be accessible to FDACS upon request. Mosquito control aircraft operating as public aircraft not regulated by the FAA are exempt from the records referencing FAA numbers. The following need to be maintained:

1. Name and FAA license number of the licensee responsible for the pesticide application

2. Date and time of treatment

3. Location of treatment area recorded using any of the following designations:

- County, range, township, and section

- An identification system that uses maps and/or written descriptions accurately identifying the location and distinguishing the treatment area from other sites

- Legal property description

- Global positioning satellite (GPS) coordinates or longitude/latitude points that delineate the treated area

4. Name of the person requesting or authorizing the application

5. Aircraft manufacturer, make, and model

6. FAA aircraft registration number

7. Originating airport/airstrip

The information listed above is required only when the governor or commissioner of agriculture issues an executive order declaring an emergency in the state of Florida according to the powers granted to the governor or the commissioner of agriculture.

\section{Structural Pest Control (Ch. 482, F.S.)}

\section{Pest Control Activities}

General records requirements are outlined in the law and pertain to all applications related to structural pest control. The licensee's pest control records pertaining to pest control activities involving all pesticides, including contracts, must be kept at the licensed business location or the address specified in the application for the business license. Records for routine operations contain the following: 


\section{Information on pesticides}

\section{Amounts}

3. Uses

4. Dates

\section{Places of application}

These records are required to be kept for a period of at least two years. Those who are also licensed in the fumigation category must record this information along with the individual fumigant cylinder identification number used to fumigate the structure.

Pest control companies and limited certificate holders are also required to provide prior notification to members of the department's registry of persons who require prior notification of pesticide applications. Pesticide applicators must also provide information to the registry on the type of pesticide that will be used. The registry is updated regularly and is maintained at http://www.flaes.org/aes-ent/ memorandums.html. Although not specifically delineated in law, the department has considered this information to include the brand name and active ingredient of the pesticide being applied. This information is part of the general records required by a pest control company and/or limited certificate holder.

Pest control companies are required upon request to provide a customer with more specific information in addition to the general requirements listed above. Companies and limited certificate holders should keep these records in the event a consumer requests them. Those specific records include the business name or limited certificate holder's name; the applicator's ID card number or limited certificate number; the common or brand name of the pesticide used and the common name of the active ingredient in that pesticide; and the appropriate safety information pertaining to the pesticide product to be used, as provided on the label for the product (such as the label and material safety data sheet). Companies are also required to maintain records of other activities in the following sections.

\section{Preventive Treatments for Subterranean Termites}

Licensed applicators are required to maintain records for three years of each treatment for the prevention of subterranean termites for new construction. These records must indicate the following:

\section{Date of treatment}

2. Address of property treated

3. Total square footage of structure treated

4. Pesticide used

5. Percent concentration of mixture applied

6. Total volume applied

Applicators must also have records of all termiticides purchased, obtained, or available for use, the total amount of the area treated, and the total number of sites treated using this and any other method of treatment for the prevention of subterranean termites.

\section{Wood-Destroying Organism Inspection Reports}

A wood-destroying organism inspection report must be provided by the licensee or a representative when an inspection is completed for wood-destroying organisms involving a real estate transaction and either a fee is charged for the inspection or the customer requests a written report. The report must be made or FDACS form 13645 must be filled out and furnished by the licensee. The form may be obtained at http://www.flaes.org/aes-ent/formsandpubl. html. The licensee must retain a copy of the inspection report for a minimum of three years. The inspection report must include the following information and statements:

\section{Licensee's name}

2. Date of the inspection

3. Address of the structure inspected

4. Any visible accessible areas not inspected and the reasons for not inspecting them

5. Areas of the structure that were inaccessible

6. Any visible evidence of previous treatments for, or infestations of, wood-destroying organisms

7. Identity of any wood-destroying organism present and visible damage caused

8. Statement that a notice of the inspection has been affixed to the property and a statement of the notice's location 
If any pest control treatment is provided at the time of the inspection, the inspection report must also provide the name of each wood-destroying organism targeted for treatment, the name of the pesticide used, and all conditions and terms associated with the treatment. The inspection report must also include a statement certifying that neither the inspector nor the licensee who had the inspection completed has any financial interest in the property inspected or is associated in any way in the transaction or with any party to the transaction other than for inspection purposes.

If periodic re-inspections or retreatments are specified in wood-destroying organisms preventive or control contracts, the licensee must furnish the property owner or the property owner's authorized agent a signed report after each re-inspection or retreatment. This report must include information indicating the presence or absence of wood-destroying organisms covered by the contract, whether retreatment was made, and the common or brand name of the pesticide used. There is no prescribed FDACS form to meet this requirement. Only those persons who have a FDACS identification card may perform periodic re-inspections or retreatments.

When a wood-destroying organism inspection is provided, the licensee is required to post a notice of the inspection immediately adjacent to the access to the attic or crawl area or other readily accessible area of the property inspected. This notice must be at least 3 inches by 5 inches and must consist of a material that will last at least three years. This notice must include the licensee's name and address and the date of inspection.

\section{Wood-Destroying Organism Treatment Contracts}

Pest control operators providing services for control of termites or other wood-destroying organisms are required to enter into a written contract with the property owner or an authorized agent for each treatment to control or prevent wood-destroying organisms. The operator must give the contract to the property owner or an authorized agent to accept or reject before any work is done and before payment in part or in full is received by the operator. The contract must clearly set forth the following information:

1. Complete name and address of the property owner or authorized agent and the complete address of the property to be treated

2. All buildings or structures on the property to be included for treatment
3. Complete name and business address of the licensed pest control operator

4. Date when the contract is entered, the period of time covered by the contract, and renewal option, if any

5. Complete common name(s) of the wood-destroying organism(s) to be controlled or for which preventive treatment is intended under the contract. Any contract issued after the effective date of this amendment for the treatment or prevention of termites must clearly state on the first page if the contract covers subterranean termites, dry wood termites, or both. If Formosan termites (Coptotermes formosanus) are to be excluded from coverage, this species must be named as excluded.

6. Whether the treatment is for control of an existing infestation or prevention of an infestation

7. Whether or not re-inspections are to be made under the contract and, if so, approximate time intervals between re-inspections, and fees other than renewal fees for same, if any

8. Conditions under which retreatments (for re-infestation) will be made; and conditions under which repairs will be made, if any

9. Total maximum price to be charged for the treatment, the exact annual renewal fees to be charged under the contract, if any; and the total maximum price to be charged for structural repairs, if any, shown separately

10. If the performance of the work is guaranteed by any type or form of bond, the obligations of the bond must be set forth specifically (i.e., necessary retreatments, repairs, etc., in wording identical to that in the bond itself)

11. Signature of the licensed operator or an authorized representative and the signature of the property owner or authorized agent

In contracts covering spot treatments for wood-destroying $\operatorname{organism}(\mathrm{s})$, the provisions listed above also apply. In addition to these, specific areas in, on, or under the structure to be treated must be listed in the written contract, and a statement that a spot treatment only was performed must be made on the posted treatment notice. The posted notice must be placed immediately adjacent to the access to the attic or crawl area or other readily accessible area of the property treated. This notice must be at least 3 inches by 5 
inches and consist of a material that will last at least three years.

If the certified operator will not assume responsibility for retreatment of the specific area(s) of a structure where spot treatment is made, the operator must furnish the property holder or an authorized agent with a signed statement to this effect prior to treatment.

When periodic re-inspections are specified in a wooddestroying organism preventive or control contract, the certified operator must furnish a signed report to the property owner or authorized agent after each re-inspection. This signed report must contain information on the property's condition with respect to the presence or absence of wood-destroying organisms covered by the contract and whether retreatment was made. The certified operator must retain a copy of the inspection report for at least three years.

\section{Identification Card Training Verification}

Non-certified employees who perform pest control or solicit pest control for a licensed company must have an employee identification card. Each identification cardholder must be an employee of the licensed company and work under the direct supervision of the certified operator in charge and may not be an independent contractor. Cardholders must obtain four hours of classroom training in pesticide safety, integrated pest management, and applicable federal and state laws and rules within six months after issuance of the card, or they must have received such training within two years before issuance of the card. Each cardholder must receive at least two hours of continuing training in pesticide safety, integrated pest management, and applicable federal and state laws and rules by the renewal date of the card. Certified operators and special identification cardholders for fumigation who maintain their certificates in good standing are exempt from this requirement.

A licensee or certified operator may not assign or use an employee to perform any category of pest control without providing trained supervision unless the employee is trained and qualified in that category of pest control. An employee may not perform, solicit, inspect, or apply pest control without first having been provided at least five days (40 hours) of field training in the appropriate category of pest control under the direct supervision, direction, and control of a certified operator. The training programs do not have to be pre-approved by FDACS, but are subject to audit and verification of both content and attendance.
The certified operator in charge must maintain written training records for both the initial five-day ( 40 hours) training and the continuing training requirements on all cardholders they employ. The records must be made available during routine inspections or upon the request of FDACS. Licensees must maintain the training record for at least a two-year period. The training must be conducted by a certified operator or a person under the supervision of the certified operator in charge who has been designated in writing as responsible for training. The 40 -hour initial training must be verified by one of the following:

1. Completion of FDACS form 13655, Verification Record of Initial Employee Training. The form may be obtained at http://www.freshfromflorida.com/onestop/aes/ pestcont.html.

2. A written record of 40 hours of attendance in a training course with a written course syllabus and copies of all training materials used in the course available for FDACS inspection.

FDACS will accept either of the following as documentation of continuing education training:

1. Written record of attendance on FDACS form 13662 and furnished by the licensee or trainer. The form may be obtained at http://www.flaes.org/aes-ent/formsandpubl. html. The form must accompany a complete copy of all training materials used during the training session that covers the training topics required.

2. Written record of attendance at an FDACS-approved certified operator continuing education course on form 13325 and furnished by the trainer (the form is available at http://www.flaes.org/aes-ent/formsandpubl.html).

\section{Agricultural Pest Control (Ch. 487, F.S.)}

Under the authority of the Florida Pesticide Law, FDACS requires certified pesticide applicators to maintain records relating to the application of all restricted-use pesticides. There are three classifications of applicators licensed under Ch. 487, F.S.:

- Private applicator

- Public applicator

- Commercial applicator

These requirements are unrelated to the Worker Protection Standard (WPS) requirements, which provide specific 
information to agricultural workers and pesticide handlers about applications made to agricultural plants on farms, forests, greenhouses, and nurseries.

Recordkeeping regulations in Florida require the following data be recorded by these groups of agricultural applicators for each restricted-use pesticide application:

1. Name and pesticide applicator license number of the licensee responsible for the pesticide application

2. Name of the person who actually applied the pesticide

3. Date, start time, and end time of treatment

4. Location of the treatment site, which may be recorded using any of the following designations:

- County, range, township, and section

- An identification system that uses maps and/or written descriptions accurately identifying the location of the treatment and distinguishing the treatment site from other sites

- The identification system established by the USDA found in 7 CFR 110, which uses maps and numbering systems to identify field locations

- Legal property description

5. Crop, commodity, or type of target site treated

6. Total size (in acres, square feet, acre-feet, number of animals treated, or other appropriate units) of the treatment site

7. Brand name and EPA registration number of the pesticide product applied

8. Total amount (lb., gal., etc.) of formulated product applied

\section{Application method}

10. Name of the person requesting or authorizing the application, or a statement of authority to make such application (if the application was made to property not owned or leased by the licensee)

Commercial applicators must provide a copy of the application record to the person for whom the application was made within 30 days of the restricted-use pesticide application.
Recording repetitive information that applies to all records is not necessary, as long as the information is recorded one time, and there is a written record indicating that this information applies to other applications as well.

The required information must be recorded no later than two working days after the date of application, and may be incorporated into other business transaction records. All records must be retained for a two-year period, and must be maintained in a matter accessible to authorized representatives. A suggested, but not required, form for recording applications of restricted-use pesticides may be obtained from FDACS at http://www.flaes.org/complimonitoring/ databasesearch/pesticidecertlicensingformsanddocuments. html.

\section{Worker Protection Standard}

Agricultural establishment employers, such as those producing agricultural plants on farms, forests, greenhouses, and nurseries, are required to display pesticidespecific application information at a central location. The purpose of the information is to ensure that employees will be informed about exposure to pesticides. If workers or handler employees are on the establishment at the start of an application, the information must be displayed before the application takes place. If worker or handler employees are not on the establishment at the start of an application, the information is to be displayed no later than the beginning of their first work period. The following information for all pesticides used must be displayed:

1. Location and description of the area to be treated

2. Product name

3. EPA registration number

4. Active ingredient(s) of the pesticide

5. Time and date the pesticide is scheduled to be applied

6. Restricted-entry interval for the pesticide

The information must be displayed whenever any worker or pesticide handler employee is on the agricultural establishment and a pesticide has been applied or a restricted-entry interval has been in effect in the past 30 days. The information may be displayed continuously. A suggested, but not required, form for recording applications of pesticides to meet WPS requirements may be obtained from FDACS at http://www.flaes.org/complimonitoring/databasesearch/ pesticidecertlicensingformsanddocuments.html. 


\section{Aldicarb (Temik) Permits}

In addition to records of restricted-use pesticides, individuals who obtain Aldicarb (Temik) permits are required to keep the approved permit and any associated attachments (maps, well construction documentation, etc.) for two years. Permit records must be made available to authorized FDACS representatives upon request for review, photocopying, and/or photographing. If an authorized FDACS representative requests to review these records, individuals who have obtained electronic permits using the online system may either print a copy from the website or show the website and permit screens to the FDACS representative.

\section{Aerial Applicators}

In addition to records of restricted-use pesticides, during times of a declared emergency issued by the Florida Governor or Commissioner of Agriculture, aerial applicators must keep records relating to the aerial application of all pesticides, fertilizers, and seed. This is required by Florida law and regulations. Records must contain the following information:

1. Name, FDACS pesticide applicator license number, and FAA license number of the licensee responsible for the application

2. Date, start time, and end time of treatment

3. Location of treatment site, which may be recorded using any of the following:

- County, range, township, and section

- An identification system that uses maps and/or written descriptions accurately identifying the location and distinguishing the treatment site from other sites

- Legal property description

- Global positioning satellite (GPS) coordinates or longitude/latitude points that delineate the treated area

4. Name of the person requesting or authorizing the application

\section{Aircraft manufacturer, make, and model}

6. FAA aircraft registration number

7. Originating airport or airstrip
The above information must be maintained for two years following application in a manner accessible by FDACS upon request.

\section{Organo-Auxin Herbicide Rule}

In addition to records of restricted-use pesticides, persons making spray applications of organo-auxin herbicides to cumulative land or water surface areas exceeding 5 acres per 24-hour period are required to maintain the following records for two years:

1. Name and address of the owner, lessee, or tenant in control of the land, and the name and address of the applicator

2. Location of the site to be treated, location of the herbicide mixing and loading area, and description of application equipment used

3. Date and time of application

4. Trade name, manufacturer, formulation, total amount of product to be applied per acre, and the amount of active ingredient of the product applied per acre

5. Total acreage and crop or site treated

6. Average hourly wind speed and direction

7. Nozzle type, including gallons per minute rating at specified pressure (usually $40 \mathrm{psi}$ ) and angle of spray emission if applicable

\section{Pesticide Dealers}

Licensed pesticide dealers must maintain the following records related to the sale or exchange of restricted-use pesticides:

1. Date of sale

2. Name and license number of licensed applicator making or authorizing the purchase

3. Name of authorized purchase agent purchasing the pesticide product, if applicable

4. Brand name and EPA registration number of each product sold or exchanged

5. Size and number of containers of each product sold or exchanged 
6. Date and location where delivery was made if the pesticide dealer delivered the product to a location not on the premises of the dealership

The information listed in (1) through (5) should be recorded immediately at the time of sale or exchange and may be incorporated into billing invoices or other business transaction records. The information required in (6) should be recorded immediately after product delivery, when applicable, and may be incorporated into billing invoices or other business transaction records.

Pesticide dealers are required to retain all of the recorded information for two years following the date of sale or exchange in a manner accessible by authorized FDACS representatives. If an authorized FDACS representative submits a written request, a licensed dealer must provide the records required to be maintained under this rule and permit the authorized representative to copy or photograph any of the records. The original records shall be maintained by the licensed dealer.

\section{Pesticide Secondary Containment}

The following requirements are applicable to both dry pesticide containment and pesticide dispensing areas. Facility owner/operators must maintain the following records and must furnish these records for inspection and copying upon request by an EPA representative. Records of inspection and maintenance for each containment structure and for each stationary pesticide container and its appurtenances must be kept for three years and include the following information:

1. Name of the person conducting the inspection or maintenance

2. Date the inspection or maintenance was conducted

\section{Conditions noted}

4. Specific maintenance performed

5. Records for any non-stationary pesticide container that holds undivided quantities of agricultural pesticides equal to or greater than $4,000 \mathrm{lb}$ of dry pesticide, but is not protected by a secondary containment unit meeting these regulations, must be kept for three years. Records on these non-stationary containers must include the time period that the container remains at the same location.
Records of the construction date of the containment structure must be kept for as long as the pesticide containment structure is in use and for three years afterwards.

\section{Additional Information}

Aerts, M. A., O. N. Nesheim, and F. M. Fishel. 2012. Pesticide Recordkeeping. PI-20. Gainesville: University of Florida Institute of Food and Agricultural Sciences. http://edis.ifas. ufl.edu/pi012.

Fishel, F. M. 2011. Licensing of Pesticide Dealers in Florida. PI-49. Gainesville: University of Florida Institute of Food and Agricultural Sciences. http://edis.ifas.ufl.edu/pi086.

Fishel, F. M. 2011. Requirements of Aerial Applicators in Florida. PI-58. Gainesville: University of Florida Institute of Food and Agricultural Sciences. http://edis.ifas.ufl.edu/ pi094.

Fishel, F. M. 2012. Worker Protection Standard: Information at a Central Location. PI-112. Gainesville: University of Florida Institute of Food and Agricultural Sciences. http:// edis.ifas.ufl.edu/pi149.

Fishel, F. M. 2013. Specifically Regulated Pesticides in Florida - Aldicarb. PI-74. Gainesville: University of Florida Institute of Food and Agricultural Sciences. http://edis.ifas.ufl.edu/ pil11.

Fishel, F. M., J. A. Ferrell, G. E. MacDonald, and B. J. Brecke. 2012. Florida's Organo-Auxin Herbicide Rule - 2012. SS-AGR-12. Gainesville: University of Florida Institute of Food and Agricultural Sciences. http://edis.ifas.ufl.edu/ wg051.

Nesheim, O. N., and F. M. Fishel. 2012. Registry of Persons Requiring Prior Notification of the Application of Pesticides. PI-5. Gainesville: University of Florida Institute of Food and Agricultural Sciences. http://edis.ifas.ufl.edu/pi004.

Wells, B. C., and F. M. Fishel. 2012. Refillable Containers and Secondary Containment Requirements for Agricultural Pesticides in Florida. PI-240. Gainesville: University of Florida Institute of Food and Agricultural Sciences. http:// edis.ifas.ufl.edu/pi240. 